\title{
A importância do conhecimento organizacional para o processo de inovação no modelo de negócio
}

\section{RESUMO}

O presente trabalho explora a relação entre conhecimento organizacional e inovação no modelo de negócio. Mais precisamente, sugere que as organizações que decidem inovar em seus modelos de negócio podem se beneficiar se considerarem o conhecimento que armazenam em seus repositórios como um insumo importante para o processo de inovação. Um mapeamento bibliométrico permitiu que os autores identificassem os artigos mais relevantes que tratam dos dois temas centrais da pesquisa. Como resultado da análise desses trabalhos, são listados e detalhados seis fatores que potencializam as chances de sucesso das iniciativas de inovação no modelo de negócio. Não por coincidência, cinco deles têm relação direta com o conhecimento organizacional.

Palavras-chave: Conhecimento, repositório de conhecimento, gestão do conhecimento, modelo de negócio, inovação.

\section{ABSTRACT \\ THE IMPORTANCE OF ORGANIZATIONAL KNOWLEDGE FOR THE INNOVATION PROCESS IN BUSINESS MODEL}

This research explores the relation between organizational knowledge and innovation in the business model. More precisely, it suggests that organizations which decide to innovate in their business models can benefit in the process if they take into account the knowledge they store in their repositories as a source for the innovation process. A bibliometric mapping allowed the authors to identify most relevant articles dealing with the two main themes of the research. As a result of the analysis of these articles the authors listed and presented in detail six factors that potentialize the chances for sucess in the innovation process of the business model. It was not a coincidence that five amongst these factors relate to organizational knowledge.

Keywords: knowledge, knowledge repository, knowledge management, business model, innovation.

Heron Jader Trierveiler

heronjt@gmail.com

Mestrando, Universidade Federal de Santa Catarina

Denilson Sell

denilson@stela.org.br

Doutor, Universidade Federal de Santa Catarina

Roberto Carlos dos Santos Pacheco

pacheco@egc.ufsc.br

Doutor, Universidade Federal de Santa Catarina 


\section{Introdução}

Uma hipótese norteou as pesquisas e a redação deste artigo: a de que existe uma relação positiva entre conhecimento organizacional e inovação no modelo de negócio. De forma geral, acreditamos que as organizações que decidem inovar em seus modelos de negócio seriam beneficiadas caso considerassem o conhecimento que armazenam em seus repositórios como um importante insumo desse processo.

De forma explícita, a academia pouco explorou a relação entre conhecimento organizacional e modelo de negócio. Por isso, achamos por bem realizar um mapeamento bibliométrico que nos permitisse selecionar os principais trabalhos das duas áreas. Consideramos como elementos de busca não somente os dois conceitos centrais, mas também alguns adjacentes como ativos de conhecimento, gestão do conhecimento, repositórios de conhecimento e inovação no modelo de negócio. Da análise dos trabalhos mais relevantes, pudemos evidenciar relações que contribuem para a validação de nossa hipótese e propor sugestões de pesquisas futuras nesta área de investigação científica.

Na seção que sucede esta introdução, apresentamos a metodologia adotada para a realização das pesquisas. Nas seguintes, abordamos os principais conceitos relacionados às duas construções teóricas que sustentam este trabalho: conhecimento organizacional e modelo de negócio. Da primeira, além dos conceitos gerais, dissertamos sobre gestão do conhecimento, sistemas de apoio à gestão do conhecimento e repositórios de conhecimento. Da segunda, atemo-nos aos componentes do modelo de negócio e à inovação no modelo de negócio.

Ao final, detalhamos como, a partir da análise dos trabalhos, pode ser aceita como válida (e positiva) a relação entre conhecimento organizacional e modelo de negócio. Mais precisamente, listamos e descrevemos seis fatores que têm maior potencial para determinar o sucesso das iniciativas de inovação no modelo de negócio. Cinco são referentes ao conhecimento organizacional.

\section{Metodologia}

Com o objetivo de validar a hipótese de que existe uma oportunidade interessante de pesquisa na intersecção entre conhecimento organizacional e inovação no modelo de negócio, realizamos um mapeamento bibliométrico em três etapas:

i. coleta dos dados;

ii. análise descritiva dos dados coletados; e

iii. apresentação dos resultados.

A coleta dos dados foi realizada pela busca sistemática na base de dados ISI Web of Science. Optamos por referida base, principalmente, pela sua reconhecida relevância acadêmica e pela amplitude do seu conteúdo.

As bases de citações disponibilizadas pela ISI Web of Science utilizadas para a pesquisa foram a Social Sciences Citation Index e a Conference Proceeding Citation Index - Social Science \& Humanities. Nas análises preliminares, verificamos um acréscimo significativo de publicações quando consideramos também essa segunda base de citações. Decorreu daí a decisão de incluí-la no escopo da pesquisa.

A estratégia de busca, por sua vez, consistiu na execução de etapas que responderam ao objetivo principal do mapeamento na ordem apresentada a seguir:

a) Busca com base nos termos "organi?ational knowledge" em títulos, palavras-chave e resumos das publicações (topic) sem corte temporal.

b) Busca com base nos termos "business model" AND knowledge em títulos, palavras-chave e resumos das publicações (topic) sem corte temporal.

c) Combinação dos resultados das duas buscas, utilizando a opção de seleção "or" com vistas a evitar a duplicação dos resultados.

O símbolo "?", em "organi?ational", foi utilizado com a única intenção de considerar, nos resultados da busca, tanto a grafia americana (organizational) quanto a britânica (organisational).

Cumpridas essas etapas, procedemos com a leitura dos trabalhos mais relevantes e estruturação dos dados para análise, apresentação e sugestão de pesquisas futuras. Os resultados estão distribuídos nas próximas seções deste texto. 


\section{Análise e discussão dos resultados}

O mapeamento bibliométrico permitiu que identificássemos os principais trabalhos publicados sobre conhecimento organizacional, modelo de negócio e a intersecção entre ambas as áreas.

Nas seções seguintes, apresentamos os principais resultados das análises realizadas com base nesses trabalhos. Abordamos, de forma geral, os principais conceitos e definições e, em seguida, tratamos especificamente de gestão do conhecimento, repositórios de conhecimento, componentes do modelo de negócio e inovação no modelo de negócio.

Ao final, amparamo-nos nos fatores que potencializam o sucesso das iniciativas de inovação no modelo de negócio para dissertar sobre a validade da hipótese que estabelece uma relação positiva entre conhecimento organizacional e inovação no modelo de negócio.

\section{Conhecimento organizacional}

O conhecimento tem sido objeto de investigação científica de várias disciplinas ao longo dos últimos séculos. Sua gênese se deu na filosofia, e epistemologistas dedicaram-se largamente à tarefa de conceituá-lo. Nas duas últimas décadas, o conhecimento passou a ser alvo também de pesquisadores das disciplinas de gestão. Por nos aproximarmos desse segundo grupo, enfatizamos neste trabalho a aplicação do conhecimento no contexto das organizações e preferimos não dissertar exaustivamente a respeito de sua conceituação.

Nos estudos organizacionais publicados nas últimas décadas, evidenciam-se muitas discussões sobre conhecimento organizacional e temas adjacentes, como organizações baseadas em conhecimento, organizações criadoras de conhecimento e trabalho intensivo em conhecimento. São vários, igualmente, os temas correlatos, como aprendizagem organizacional, mente coletiva (Weick \& Roberts, 1993) e cérebro organizacional. Cook e Brown (1999) afirmam que se tornou comum falar em conhecimento no contexto tanto de indivíduos quanto de grupos e considerar conhecimento nos sentidos explícito e tácito (o conhecimento explícito é tratado como o que pode ser declarado ou formalizado, e o tácito como aquele associado às habilidades ou know-how). Existem, ainda, discussões sobre como o conhecimento explícito adquirido pelos indivíduos em uma organização pode ser associado à aprendizagem no nível da organização (March \& Olsen, 1976; Argyris \& Schon, 1978; Sims \& Gioia, 1986; Simon, 1991; Sitkin, 1992), como as habilidades tácitas de um indivíduo podem ser aproveitadas em benefício da organização (Nonaka, 1994; Nonaka \& Takeuchi, 1995; Spender, 1996) e como as atividades de grupos podem promover a aprendizagem organizacional (Weick, 1991; Weick \& Westley, 1996). Tais conceitos, ainda segundo a opinião de Cook e Brown (1999), são tão vitais para os estudos organizacionais quanto os de gerenciamento do capital intelectual (Stewart, 1997), das competências essenciais (Hamel \& Prahalad, 1994) e da inovação (Leonard-Barton, 1995).

Orlikowski (2002) prefere classificar as pesquisas sobre o conhecimento organizacional em duas abordagens. A primeira argumenta que as organizações possuem diferentes tipos de conhecimento e que sua identificação e análise proporcionam meios mais eficientes de gerá-los, compartilhá-los e gerenciá-los. A classificação do conhecimento realizada por tal abordagem costuma partir da distinção de conhecimento proposta por Polanyi (1967), isto é, conhecimento tácito e explícito. A segunda abordagem, que é defendida por Tsoukas (1996), Davenport e Prusak (1998), e Cook e Brown (1999), argumenta que os conhecimentos tácito e explícito são mutuamente constituídos e não podem ser separados. Esses autores veem o conhecimento organizacional de forma processual, disperso e inerentemente indeterminado (Orlikowski, 2002).

Já Nonaka (1994), precursor e inspirador de muitos estudos a propósito do conhecimento organizacional, defende que a organização seja estudada sob o ponto de vista de como ela cria informação e conhecimento, em vez de considerar somente o processo pelo qual ela processa essas entidades. A criação de novos conhecimentos se dá pela reconstrução das perspectivas, dos frameworks e das premissas existentes.

Outro ponto tratado amplamente pelos estudiosos das organizações diz respeito às organizações fundamentadas em conhecimento e sua relação com a teoria das organizações baseadas em recursos. Dessa relação, decorre que a perspectiva das organizações cuja base é o conhecimento não só toma a teoria das organizações baseadas em curso como fundamento, mas também a complementa (Alavi \& Leidner, 2001). Essa segunda abordagem (Wernerfelt, 1984) sugere, essencialmente, que as ações estratégicas que reposicionam a organização requerem que 
ela possua recursos, competências e aptidões muito específicos (Spender, 1996).

A perspectiva das organizações baseadas em conhecimento parte do pressuposto de que o conhecimento é um recurso normalmente difícil de imitar e socialmente complexo e que, por isso, esses ativos podem proporcionar vantagem competitiva sustentável em longo prazo. Entretanto, é menos o conhecimento existente em um dado período de tempo do que a habilidade da organização em criar novo conhecimento e aplicá-lo que fornece as bases para o alcance da vantagem competitiva (Alavi \& Leidner, 2001).

Na próxima seção, complementamos esta breve contextualização apresentando conceitos e definições sobre gestão do conhecimento, sistemas de apoio ao conhecimento e repositórios de conhecimento.

\section{Principais conceitos e definições}

Sob um viés bastante pragmático, Davenport e Prusak (1998) abordam o conhecimento como uma mistura fluida de experiência condensada, valores, informação contextual e insight experimentado que oferece uma estrutura para avaliação e incorporação de novas experiências e informações. Nonaka (1994), por sua vez, prefere uma conceituação mais genérica, apresentando o conhecimento simplesmente como crença verdadeira e justificada.

Também amparado pelo trabalho de Polanyi (1967), Nonaka (1994) argumenta que o conhecimento organizacional é criado por meio de um diálogo contínuo entre os conhecimentos tácito e explícito. De forma geral, o conhecimento explícito é aquele que pode ser transmitido em linguagem formal e sistemática. O conhecimento tácito, por ser enraizado na ação, no compromisso e no envolvimento com um contexto específico, não é facilmente formalizado.

Alavi e Leidner (2001) lembram que a classificação do conhecimento como tácito e explícito é largamente citada, mas existem outras. Alguns se referem ao conhecimento como declarativo (know-about) (Nolan Norton Institue, 1998), causal (know-why), condicional (know-when) e relacional (know-how) (Zack, 1998).

Em um nível fundamental, o conhecimento é criado por indivíduos. Uma organização não pode criar conhecimento sem indivíduos. Cabe à organização apoiar indivíduos criativos ou oferecer um contexto para que tais indivíduos criem conhecimento. O conhecimento está nos indivíduos, mas pode ser expresso igualmente em normas pela cooperação dos membros em uma comunidade social (grupo, organização ou rede). O conhecimento da organização é relativamente observável; regras operacionais, tecnologias de manufatura e bases de dados de clientes são representações tangíveis desse conhecimento (Kogut \& Zander, 1992).

Cabe salientar, ainda, que a criação de conhecimento organizacional deve ser compreendida em termos de um processo que, organizacionalmente, amplifica o conhecimento criado por indivíduos e o solidifica como uma parte do conhecimento da organização (Nonaka, 1994). Distintamente da criação de conhecimento em nível individual, a criação de conhecimento organizacional acontece quando os quatro modos de criação de conhecimento são organizacionalmente gerenciados para a criação de um ciclo contínuo.

A espiral do conhecimento, proposta por Nonaka (1994), apresenta os quatro modos de conversão do conhecimento:

i. de tácito para tácito pela socialização;

ii. de explícito para explícito pela combinação;

iii. de tácito para explícito pela externalização; e

iv. de explícito para tácito pela internalização. 
A Figura 1 esquematiza graficamente a espiral de conversão do conhecimento.

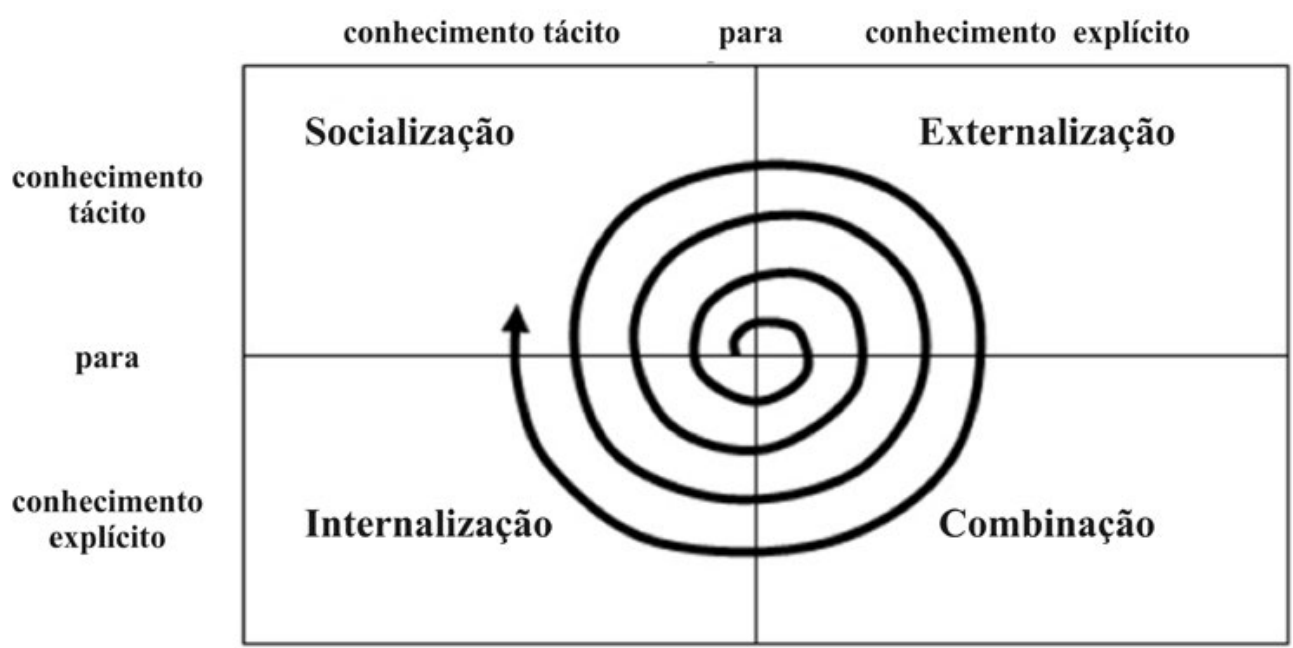

Figura 1: espiral do conhecimento.

Fonte: adaptado de Nonaka (1994).

Enquanto a criação de conhecimento organizacional é um processo contínuo e sem um fim delimitado, é interessante, também, que a organização promova o compartilhamento de conhecimento para além dos seus limites. O objetivo principal será sempre a criação de mais conhecimento. Para que isso ocorra, a organização pode se valer de mecanismos formais de criação de conhecimento em nível interorganizacional. Exemplos de mecanismos são a formação de alianças e o outsoucing, que fortalecem a conexão entre clientes, fornecedores, distribuidores e até de concorrentes (Nonaka, 1994).

A criação eficiente de conhecimento requer o acesso e o pré-processamento rápidos de informação e conhecimento já existentes (Nonaka, 1994). Por isso, ele deve ser organizado para facilitar tanto o acesso quanto a recuperação de conteúdo (Alavi \& Leidner, 2001). Dessa ordem, decorre a importância das políticas e dos sistemas de apoio à gestão do conhecimento, sobre os quais trataremos na próxima seção deste capítulo.

\section{Gestão do conhecimento e sistemas de apoio à gestão do conhecimento}

A Gestão do Conhecimento $(\mathrm{GC})$ refere-se à identificação e à alavancagem do conhecimento coletivo em uma organização para ajudá-la a competir ou a se adaptar a externalidades (von Krogh, 1998 citado por Alavi \& Leidner, 2001). Ela propõe, essencialmente, potencializar a inovação e a capacidade de resposta da organização a fatores externos (oportunidades de mercado, novas regulações).

A GC é composta de processos distintos, mas interdependentes, de criação, armazenamento, recuperação, transferência e aplicação de conhecimento (Alavi \& Leidner, 2001).

Projetos de gestão do conhecimento costumam ter pelo menos um destes três objetivos (Davenport \& Prusak, 1998):

i. tornar o conhecimento visível e mostrar o papel do conhecimento em uma organização, principalmente por meio de mapas, páginas amarelas e ferramentas de hipertexto;

ii. desenvolver uma cultura intensiva em conhecimento pelo encorajamento e promoção de comportamentos como a troca de conhecimento e a procura e oferta proativa de conhecimento;

iii. construir uma infraestrutura de conhecimento - não somente um sistema técnico, mas uma rede de conexões entre pessoas oferecendo-lhes espaço, tempo, ferramentas e encorajandoas a interagir e colaborar.

Tornou-se comum nas últimas décadas o desenvolvimento de tecnologias de informação para o aperfeiçoamento da GC. Projetos dessa natureza exigem que se tenha atenção não somente ao aperfeiçoamento dos processos de criação e armazenamento de conhecimento nos níveis individual e de grupo, mas, também, ao aperfeiçoamento das conexões entre indivíduos e entre grupos (Alavi \& Leidner, 1998).

De forma geral, sistemas de apoio à gestão do conhecimento (em inglês, KMS) referem-se a uma classe de sistemas de informação que apoia a gestão do conhecimento nas organizações. 
Eles podem auxiliar na procura de um especialista ou de uma fonte de conhecimento, utilizando diretórios on-line ou buscas em bancos de dados; compartilhamento de conhecimento e trabalho colaborativo em equipes virtuais; acesso à informação de projetos passados e aprendizagem sobre necessidades e comportamentos dos clientes pela análise de dados transacionais (KPMG Management Consulting, 1998 citado por Alavi \& Leidner, 1998).

Alavi \& Leidner (1998), novamente, apresentam uma perspectiva interessante acerca da relação entre a percepção sobre GC e o desenvolvimento de sistemas de apoio à GC. Eles frisam que o desenvolvimento de tais sistemas deve considerar diferentes perspectivas, pois elas o orientarão. Se o conhecimento é visto como um objeto, ou é equivalente ao acesso à informação, tais sistemas devem focar na construção e no gerenciamento de repositórios de armazenamento de conhecimento. Se a organização opta pela perspectiva do conhecimento como um processo, os sistemas de apoio à GC devem focar no fluxo de conhecimento e nos processos de criação, compartilhamento e distribuição de conhecimento.

\section{Repositórios de conhecimento}

Ainda que a tríade codificação, armazenamento e transmissão de conhecimento nas organizações não seja nova, só recentemente as práticas organizacionais e gerenciais tornaramse mais focadas em conhecimento. $O$ primeiro dos seus elementos possui um conceito adjacente importante - o de codificabilidade (em inglês, codifiability). Ele se refere à habilidade da organização de estruturar o conhecimento em um conjunto de regras identificáveis e relacionamentos que podem ser facilmente comunicados (Kogut \& Zander, 1992).

Ainda que não pretendamos tratar exaustivamente, neste texto, sobre o conceito de memória organizacional, cabe apresentá-la brevemente, pois possui estreita relação com a ideia de codificabilidade do conhecimento. A memória de uma organização é composta pelo conhecimento que reside em vários componentes, incluindo documentos escritos, informação estruturada armazenada em bancos de dados eletrônicos, conhecimento humano codificado armazenado em sistemas especialistas, procedimentos organizacionais documentados e processos e conhecimento tácito adquirido por indivíduos e redes de indivíduos. Uma das classificações aceitas pela comunidade científica distingue-a entre semântica ou episódica. A semântica refere-se ao conhecimento genérico, explícito e articulado (arquivos organizacionais de relatórios anuais). A episódica diz respeito a contextos específicos e conhecimentos situados (circunstâncias específicas de decisões organizacionais e suas consequências, lugar e tempo) (Alavi \& Leidner, 1998).

\section{Modelo de negócio}

Recentemente, as discussões acadêmicas publicadas nos campos da gestão estratégica, da inovação, do empreendedorismo e da teoria econômica incorporaram o conceito de modelo de negócio. Esse interesse é representado pelo aumento significativo de publicações que fazem referência a "modelo de negócio" a partir, principalmente, do fim dos anos 1990 (Zott, Amit \& Massa, 2011).

Importante salientar que não só a academia, mas, também, o universo empresarial têm levantado discussões a respeito do modelo de negócio, e essa realidade foi comprovada por uma pesquisa conduzida e publicada pela IBM em 2006. Os resultados indicaram que, ainda que os líderes empresariais insistam em definir seus negócios em termos dos produtos e serviços, $30 \%$ dos esforços que as empresas consultadas despenderão em inovação nos próximos anos serão direcionados à inovação em modelos de negócios. Os principais fatores que ajudam a explicar tal tendência são as oportunidades e ameaças apresentadas pelos avanços tecnológicos, pela globalização e, até, por novas regulamentações (IBM, 2006).

A esquematização do modelo de negócio é uma decisão-chave para um empreendedor que cria uma nova companhia e uma tarefa crucial, ainda que mais difícil, para os gestores que são desafiados a repensar seus antigos modelos para preparar suas companhias para o futuro (Zott \& Amit, 2010).

Dissertamos sobre o conceito de modelo de negócio em três seções: (i) uma que resgata os principais conceitos e definições; (ii) outra que lista e detalha os elementos mais comuns de um modelo de negócio e, a última, (iii) que discute os principais tópicos sobre inovação em modelos de negócio. 


\section{Principais conceitos e definições de modelo de negócio}

Já é significativo o número de autores que trabalham com o conceito de modelo de negócios. Ainda que não tenham chegado a um entendimento comum quanto à sua definição, grande parte dos trabalhos relaciona modelos de negócios à lógica fundamental de uma empresa para criação e captura de valor (Chesbrough \& Appleyard, 2007; IBM, 2006; Johnson, Christensen \& Kagerman, 2008; Voelpel et al., 2004; Zott \& Amit, 2010; Casadesus-Masanell \& Ricart, 2010).

Teece (2010) apresenta uma definição mais ampla e completa. Além da lógica para criação e captura de valor, segundo ele, o modelo de negócios determina a arquitetura de receitas, custos e lucros associados à entrega de valor pela organização. Em essência, compreende suas arquiteturas organizacional e financeira.

Em trabalhos publicados recentemente, é evidente a preocupação dos autores em estabelecer a relação entre modelo de negócios e estratégia organizacional. Essa relação serve a dois grandes propósitos. Primeiramente, quando relacionam os conceitos, os autores salientam a importância de estudá-los conjuntamente. Segundo, justamente por relacioná-los, esclarecem o equívoco tão comum de confundi-los e tratá-los como um conceito só. Nessa linha de pensamento, resta lembrar que o modelo de negócios não é uma estratégia, mas considera questões estratégicas, traduzindoas em um modelo conceitual que explicitamente ilustra como funciona o negócio (Osterwalder, Pigneur \& Tucci, 2005; Hacklin \& Wallnöfer, 2012; Lambert \& Davidson, 2013).

\section{Componentes do modelo de negócio}

Da mesma forma que os principais trabalhos publicados sobre modelo de negócio não apresentam uma conceituação única e consensual, evidencia-se certa divergência, ainda que não muito profunda, acerca dos elementos que o compõem.

Johnson et al. (2008) estruturam o modelo de negócio pela composição de quatro elementos:

i. Proposição de valor para o cliente

Uma empresa de sucesso é aquela que encontrou a fórmula para a criação de valor para os clientes - isto é, uma forma pela qual pode ajudá-los a ter uma necessidade satisfeita.

ii. Estrutura de lucros

A estrutura de receita é o esquema que define como uma empresa cria valor para si enquanto cria valor também para seus clientes (modelo de receitas, estrutura de custos, etc.).

iii. Recursos-chave

Os recursos-chave são ativos, como pessoas, tecnologias, produtos, equipamentos, canais e marca necessários à oferta da proposição de valor ao público-alvo da empresa.

iv. Processos-chave

Empresas de sucesso realizam processos operacionais e gerenciais que lhe permitem entregar valor de forma bem-sucedida repetidamente e em escala. Compreendem processos de treinamento, desenvolvimento, manufatura, orçamentário, planejamento, vendas e serviços.

Wirtz, Schilke e Ullrich (2010) preferem trabalhar os elementos do modelo de negócio de forma mais genérica e sugerem sua compreensão pela composição de vários submodelos ou domínios. Desse modo, o modelo de negócio deve especificar quais recursos adentram a companhia (domínio de recursos), como eles são transformados (domínio de criação de valor) em produtos e serviços comercializáveis (domínio da oferta de valor), como esses produtos e serviços são disponibilizados ao consumidor (domínio da distribuição) e como as receitas são geradas e obtidas pelos sócios do negócio (domínio de receitas).

Já Morris, Schindehutte e Allen (2005) argumentam ludicamente que um bom modelo de negócio deve responder a seis questões-chave sobre a empresa ou organização:

i. Como ela criará valor?

ii. Para quem ela criará valor?

iii. Qual é a sua fonte interna de vantagem competitiva?

iv. Como ela se posicionará no mercado?

v. Como ela ganhará dinheiro?

vi. Quais são as ambições dos empreendedores em termos de tempo, escopo e tamanho?

Além de mencionar os componentes de um modelo de negócio, Teece (2010) vai além e sugere ainda o processo que pode orientar a sua esquematização. De acordo com o autor, atrelar a análise da estratégia competitiva ao design do modelo de negócio requer que se segmente o mercado, que se crie uma proposição de valor para cada segmento, que se estabeleça o aparato 
necessário à entrega de valor e, então, que se proponham vários mecanismos isolados que podem ser usados para prevenir que o modelo de negócio seja enfraquecido por meio da imitação pelos competidores ou pela desintermediação dos consumidores.

Entretanto, foi Osterwalder (2004), em tese defendida na Universidade de Lausanne, e nas publicações subsequentes (Osterwalder et al., 2005; Osterwalder, Pigneur \& Smith, 2010), quem parece ter realizado o levantamento e a análise mais robustos a respeito dos componentes de um modelo de negócio. É igualmente dele a prerrogativa de ser o autor mais lembrado nos meios não acadêmicos nas discussões referentes a mencionado assunto. Principalmente por ter analisado uma quantidade significativa de publicações, apresentamos, no Quadro 1, os nove elementos do modelo de negócio proposto por Osterwalder et al. (2005).

Quadro 1

Framework para definição e inovação no modelo de negócio

\begin{tabular}{|c|c|c|}
\hline Pilar & $\begin{array}{l}\text { Área do modelo de negócio } \\
\text { (building block) }\end{array}$ & Descrição \\
\hline Produto & Proposição de valor & $\begin{array}{l}\text { Oferece uma visão geral do portfólio de } \\
\text { produtos e serviços de uma organização. }\end{array}$ \\
\hline \multirow{3}{*}{ Clientes } & Segmentos de clientes & $\begin{array}{l}\text { Descreve os segmentos de clientes para os } \\
\text { quais uma organização deseja oferecer valor. }\end{array}$ \\
\hline & Canais & $\begin{array}{l}\text { Descreve os vários meios pelos quais uma } \\
\text { organização interage com seus clientes. }\end{array}$ \\
\hline & $\begin{array}{l}\text { Relacionamento com os } \\
\text { clientes }\end{array}$ & $\begin{array}{l}\text { Explica os tipos de conexões que uma } \\
\text { organização estabelece entre ela e seus } \\
\text { diferentes segmentos de clientes. }\end{array}$ \\
\hline \multirow{3}{*}{$\begin{array}{l}\text { Infraestrutura de } \\
\text { gestão }\end{array}$} & Atividades-chave & $\begin{array}{l}\text { Descreve o arranjo de atividades necessário } \\
\text { à execução do modelo de negócio de uma } \\
\text { organização. }\end{array}$ \\
\hline & Recursos-chave & $\begin{array}{l}\text { Esboça os recursos, principalmente em termos } \\
\text { de competências, necessários à execução do } \\
\text { modelo de negócio de uma organização. }\end{array}$ \\
\hline & Rede de parceiros & $\begin{array}{l}\text { Retrata a rede de acordos cooperativos com } \\
\text { outras organizações necessários à oferta e } \\
\text { comercialização eficiente de valor. }\end{array}$ \\
\hline \multirow{2}{*}{ Finanças } & Estrutura de custos & $\begin{array}{l}\text { Resume as consequências monetárias } \\
\text { necessárias à viabilização de um modelo de } \\
\text { negócio. }\end{array}$ \\
\hline & Fluxo de receitas & $\begin{array}{l}\text { Descreve a forma pela qual uma organização } \\
\text { recebe retorno financeiro por meio de uma } \\
\text { variedade de fluxos de receita. }\end{array}$ \\
\hline
\end{tabular}

Fonte: Adaptado de Osterwalder et al. (2005)

\section{Inovação no modelo de negócio}

Por que as empresas e organizações ainda não se beneficiam do crescimento que pode ser promovido pela inovação no modelo de negócio? É com base nesse questionamento que Johnson et al. (2008) tratam da inovação no modelo de negócio e das circunstâncias que exigem essa necessidade de mudança. Segundo eles, tal questionamento pode ser respondido pelo fato de poucos estudos, até hoje, terem se aprofundado na dinâmica e nos processos de desenvolvimento do modelo de negócio. Além disso, são poucas as empresas e organizações que compreendem suficientemente bem seus próprios modelos de negócio (a premissa por trás de sua criação, suas interpendências, suas forças e limitações).

Uma perspectiva emergente vê o desenvolvimento do modelo de negócio como um experimento inicial seguido pela sua constante revisão, adaptação e refinamento baseados na aprendizagem por tentativa e erro. É comum que empresas e organizações consolidadas iniciem tal processo de experimentação como uma reação a dificuldades que elas vêm enfrentando. Até mesmo depois do modelo de negócio ter se estabelecido, estando em uso por algum tempo, novas variáveis internas ou externas podem desafiar sua viabilidade e as perspectivas futuras 
(Sosna, Trevinyo-Rodriguez \& Velamuri, 2010). Se a inovação no modelo de negócio demanda experimentação, que requer investimentos, as empresas e organizações precisarão se tornar mais complacentes com ferramentas financeiras que fazem sentido em um mundo de experimentação. Disso implica que as decisões nesse contexto serão baseadas muito menos em conceitos determinísticos - como projeção de valor agregado e valor presente líquido - e muito mais em teorias como a das opções reais (McGrath, 2010).

Ainda que seja impossível determinar as variáveis que exigem que uma empresa ou organização inove no seu modelo de negócio, cabe resgatar algumas circunstâncias em que é comum que isso ocorra. A seguir, mencionamos algumas delas extraídas de publicação de Johnson et al. (2008):

i. A oportunidade de suprir, por meio da inovação radical, as necessidades de um grande grupo de potenciais consumidores marginalizados de um mercado porque as soluções existentes são muito caras ou complicadas para sua realidade. Isso inclui a oportunidade de democratizar produtos em mercados emergentes.

ii. A oportunidade de capitalizar uma tecnologia inovadora, viabilizando-a por meio de um novo modelo de negócio, ou a oportunidade de alavancar uma tecnologia já testada, ofertando-a para um mercado novo.

iii. A oportunidade de resolver um problema específico de um segmento de mercado ainda não atendido.

iv. A necessidade de afastar potenciais concorrentes.

v. A necessidade de responder a um cenário no qual a concorrência está estremecida.

Por fim, Giesen et al. (2010 citado por Lambert \& Davidson, 2013) concluíram que as inovações no modelo de negócio são bem-sucedidas quando: (i) são bem alinhadas interna e externamente; (ii) baseiam-se em análises sofisticadas que continuam sendo monitoradas durante o tempo; e (iii) são esquematizadas para serem adaptáveis.

\section{Relação entre conhecimento organizacional e inovação no modelo de negócio}

Já mencionamos nas seções anteriores que este artigo tem por objetivo apresentar e dissertar sobre a validade da hipótese que estabelece uma relação positiva entre conhecimento organizacional e inovação no modelo de negócio. Mais precisamente, acreditamos que as organizações se beneficiariam se considerassem o conhecimento que armazenam em seus repositórios como insumo para os processos de inovação no modelo de negócio.

A literatura científica, de certa forma, sugere essa relação quando afirma que tanto o modelo de negócio quanto o conhecimento organizacional são fatores importantes para a manutenção da vantagem competitiva das organizações (Barney et al., 2001 citado por Morris et al., 2005). Ainda, por analisarem o conhecimento e as capacidades dinâmicas sob a perspectiva das organizações baseadas em recursos, os autores dessas áreas pavimentaram o caminho para o estabelecimento de mais conexões com o modelo de negócio (Nair, Nisar, Palacios \& Ruiz, 2012).

Respondemos, nas próximas seções, a um questionamento que, em nosso entendimento, ajuda a validar a hipótese norteadora deste trabalho: quais fatores têm maior potencial para determinar o sucesso das iniciativas de inovação no modelo de negócio?

É evidente que qualquer iniciativa de inovação no modelo de negócio de uma organização é peculiar e determinada pelas características próprias da organização. Todavia, acreditamos que é possível estabelecer fatores genéricos - que seriam válidos para a maioria das organizações - com potencial para influenciar positivamente as iniciativas de inovação no modelo de negócio.

Na sequência, listamos seis fatores e analisamos as razões pelas quais eles devem ser considerados pelas organizações que decidem inovar em seus modelos de negócio.

\section{1 ' fator: Conhecimento detalhado do modelo de negócio em vigor}

Para que possam propor novas formas de composição do modelo de negócio de uma organização, é essencial que as pessoas envolvidas nesse processo conheçam detalhadamente o modelo de negócio em vigor. Evidentemente, este é um fator válido somente para organizações que já estão em operação e decidem aprimorar seu modelo de negócio. Organizações nascentes, aquelas que estão em busca do melhor modelo de negócio, podem buscar inspiração em organizações que atuam no mesmo mercado ou adaptar para si modelos de negócio de organizações bem-sucedidas atuantes em outros mercados. 
Johnson et al. (2008) corroboram com tal visão ao argumentarem que, em primeiro lugar, uma compreensão detalhada do modelo de negócio em vigor é necessária para se propor uma boa forma de ajudar as pessoas a satisfazerem suas necessidades pessoais.

\section{$2^{\circ}$ fator: Incorporação do conhecimento adquirido por tentativa e erro à base de conhecimento organizacional}

É comum que modelos de negócio sejam esquematizados em workshops organizados exclusivamente para esse fim. Dessa dinâmica, surgem propostas de modelo de negócio com conteúdo, na maioria dos casos, hipotético. Chesbrough (2007) defende que a inovação no modelo de negócio não se trata de uma questão de previsão ex ante; ao contrário, ela requer uma dinâmica de tentativa e erro, e uma pequena parcela de adaptação ex post. Pela simulação e teste de possíveis modelos de negócio, gestores estarão mais preparados para o futuro (Osterwalder, 2004).

Outra recomendação da literatura sobre modelo de negócio é a experimentação estratégica. Ela é compreendida como um tipo específico de aquisição de conhecimento. Quando uma empresa já existente é desafiada a inovar em seu modelo de negócio, seus colaboradores e gestores são forçados a imaginar e aprender novas formas de fazer negócio - as mudanças são radicais e questionam a forma convencional pela qual ela faz negócio. Essa visão contrasta com a abordagem clássica de estratégia, na qual a maior parcela da aprendizagem ocorre na fase preliminar de diagnóstico por meio de análises e estudos. Entretanto, a natureza fundamental da inovação no modelo de negócio reza que simples estudos de mercado e questionários com clientes são ineficientes e pouco úteis; as pessoas respondentes são incapazes de se autoprojetar para dentro dessa "novidade radical". A experimentação estratégica oferece outra rota em favor da aprendizagem necessária e pode ser fundamental para a resolução de problemas onde as soluções são incertas ou quando as fontes de informação crítica não existem ou estão indisponíveis. $A$ realização de uma série de pequenos experimentos ajuda a minimizar o risco e maximizar os níveis de aprendizagem da empresa, tornando possível a identificação de uma estratégia potencial para o sucesso o mais eficientemente possível (Yunus, Moingeon \& Lehmann-Ortega, 2010).

No momento em que emerge um modelo de negócios viável, os conhecimentos dos indivíduos e dos grupos acumulados durante o processo de tentativa e erro devem ser integrados a toda a organização. Esta fase vê o conhecimento adquirido nos níveis individual (pelo empreendedor) e de grupo (pelos gestores), traduzidos em conhecimento organizacional; novos entendimentos e interpretações são desenvolvidos e eles se tornam cruciais à formulação e implementação de decisões estratégicas baseadas em estruturas cognitivas mais complexas (Sosna et al., 2010).

\section{$3^{\circ}$ fator: Conhecimento adquirido pelas experiências passadas}

O conhecimento anterior do empreendedor (ou do grupo gestor) e de sua equipe, obtido de suas experiências passadas e manifestado em seus mapas cognitivos, influencia as escolhas estratégicas no início de um empreendimento e na esquematização de seu modelo de negócio (Sosna et al., 2010).

Desse fato, surge a importância de envolver pessoas com experiências e, consequentemente, conhecimentos diversos na equipe responsável por conceber um novo modelo de negócio. Complementarmente, quanto mais organizados forem os repositórios de conhecimento da organização, mais facilmente os ativos de conhecimento advindos das experiências passadas serão acessados e considerados insumos para o processo de inovação.

\section{$4^{\circ}$ fator: Conhecimento das oportunidades de negócio}

A definição de modelo de negócio de Casadesus-Masanell e Ricart (2010) sustenta que o modelo de negócio descreve o conteúdo, a estrutura e a governança das transações esquematizadas para criar valor pela exploração de oportunidades de negócio. Em relação à maioria das definições, esta é peculiar por salientar que o modelo de negócio é válido se ele explora uma oportunidade de negócio.

As organizações devem possuir fortes capacidades sensitivas para identificar mudanças relevantes no ambiente de negócios em que atuam, o que requer tanto investimento em pesquisa e desenvolvimento quanto a criação de rotinas de avaliação das necessidades dos clientes e de 
possibilidades tecnológicas.

Uma vez adquiridos os conhecimentos detalhados sobre aspectos relevantes das mudanças nos ambientes de negócio, o próximo passo é alinhar essas facetas aos diferentes domínios do modelo de negócio da organização para que as oportunidades e desafios de mercado possam ser traduzidos em planos de ação que objetivam modificar partes específicas do modelo de negócio em vigor (Wirtz et al., 2010).

\section{$5^{\circ}$ fator: Flexibilidade no modelo de negócio pela incorporação de conhecimento de fontes internas e externas}

Os ativos de conhecimento que uma empresa acumula podem ampliar consideravelmente a flexibilidade do seu modelo de negócio. Nair et al. (2012) chegaram a essa conclusão quando investigaram as razões pelas quais modelos de negócio similares possuíam desempenhos diferentes mesmo quando atuavam no mesmo mercado. Os pesquisadores inferiram que $o$ desempenho das organizações decorre e depende do quão bem-sucedido o modelo de negócio é na conversão do conhecimento (entendido como um recurso) em valor. Em ambientes turbulentos e competitivos, organizações mais flexíveis têm melhor desempenho (Nair et al., 2012).

Os recursos de conhecimento que uma empresa acumula podem aumentar significativamente a flexibilidade do modelo de negócio. E essa flexibilidade é um ingrediente essencial para se compreender a diferença de desempenho entre empresas que, aparentemente, possuem modelos de negócio similares. De forma geral, são duas as fontes de recursos que as empresas podem considerar para angariar recursos: (i) o ambiente interno e (ii) o ambiente externo.

Dessa maneira, quanto maior for a propagação dos recursos baseados em conhecimento do modelo de negócio já acumulados entre os ambientes interno e externo, mais exposto e aberto o modelo de negócio será para a geração de ideias. Quanto mais flexível for o modelo de negócio, mais fácil será para a organização permitir que seu modelo de negócio assimile essas ideias e a converta em valor (Nair et al., 2012).

\section{$6^{\circ}$ fator: Investimento}

A inovação no modelo de negócio demanda experimentação, e isso requer investimento (McGrath, 2010). Este fator guarda relação direta com o $2^{\circ}$ que apresentamos neste trabalho. Modelos de negócio são concebidos com base não somente de dados e projeções estruturados, mas, também, com base em suposições das equipes envolvidas. Por essa razão, torna-se importante sua validação em um processo de tentativa e erro. Esse processo só será bem-sucedido se for respaldado pelo grupo gestor da organização na forma de investimentos.

\section{Conclusões}

Neste trabalho, propusemo-nos a investigar a relação entre conhecimento organizacional e inovação no modelo de negócio. Mais precisamente, nossa principal motivação consistia em buscar a validação da hipótese que afirma que as organizações se beneficiariam se considerassem o conhecimento organizacional como insumo no processo de inovação no modelo de negócio.

Para tanto, realizamos mapeamento bibliográfico com o objetivo de identificar como a literatura científica tem tratado de tal questão. Identificamos e analisamos, inicialmente, as publicações sobre conhecimento organizacional e temas adjacentes, como gestão do conhecimento e repositórios de conhecimento. Em seguida, concentramos nossos esforços na análise de trabalhos mais recentes que tratavam tanto dos conceitos e componentes do modelo de negócio quanto dos processos de inovação.

Esse mapeamento permitiu-nos identificar que ainda são poucos os trabalhos que estabelecem uma relação explícita entre conhecimento organizacional e inovação no modelo de negócio. Todavia, a partir da análise acurada dos principais trabalhos de ambas as áreas, acreditamos serem claras as evidências de que essa relação é válida. Elas surgem, principalmente, no momento em que são listados e descritos os seis fatores que potencializam o sucesso das iniciativas de inovação no modelo de negócio. São eles:

i. o conhecimento detalhado do modelo de negócio em vigor;

ii. a incorporação do conhecimento adquirido por tentativa e erro à base de conhecimento organizacional; 
iii. o conhecimento adquirido pelas experiências passadas;

iv. o conhecimento das oportunidades de negócio;

v. a flexibilidade no modelo de negócio pela incorporação de conhecimento de fontes internas e externas; e

vi. o investimento.

O leitor atento certamente notou que, dos seis fatores listados, cinco fazem menção direta ao conhecimento. $O$ primeiro frisa a importância de a equipe envolvida na concepção do novo modelo de negócio conhecer o modelo em vigor. O segundo resgata o caráter hipotético do modelo de negócio e a necessidade de validá-lo em um processo de tentativa e erro. Desse processo, surgem conhecimentos importantes que devem ser incorporados à base de conhecimentos da organização. Os fatores três e quatro são bastante específicos e reiteram a importância de considerar tanto o conhecimento das experiências passadas quanto o das oportunidades futuras de negócio durante a concepção do novo modelo de negócio. E o quinto, por fim, sugere que a incorporação de conhecimento de fontes internas e externas garante a flexibilidade do modelo de negócio essencial à sua adaptação a diversos contextos e importante diferencial competitivo.

Antes de apontar nossas próprias sugestões de pesquisas futuras, gostaríamos de apresentar duas já sugeridas por Lambert e Davidson (2013), e Casadesus-Masanell e Ricart (2010). Os primeiros afirmam existir oportunidades para pesquisas relacionadas à investigação das relações entre teoria estratégica e modelos de negócio, assim como do processo das inovações no modelo de negócio bem-sucedidas e suas relações com a aprendizagem organizacional, a liderança, o empreendedorismo e a gestão da mudança.

Casadesus-Masanell e Ricart (2010), por sua vez, sugerem que as pesquisas futuras decomponham os modelos de negócio em algumas partes para analisá-los isoladamente. Afirmam que diferentes grupos de decisões e consequências não interagem uns com os outros e, por isso, essa estratégia é válida.

Complementarmente aos já referidos autores, sugerimos pesquisas futuras que explorem a validade de cada um dos seis fatores que apresentamos como determinantes para o sucesso das iniciativas de inovação no modelo de negócio. Seria importante, inclusive, que tais pesquisas explorassem iniciativas empreendidas recentemente por organizações nacionais e internacionais de diferentes segmentos com vistas a analisar se os fatores são pertinentes para diferentes realidades.

Sugerimos, ainda, que as pesquisas futuras nesta área analisem quais ativos de conhecimento são insumos essenciais à inovação no modelo de negócio. De forma complementar, seria importante explorar como referido conhecimento pode ser organizado e representado para ser recuperado e utilizado pelas organizações que desejam inovar em seus modelos de negócio.

\section{REFERÊNCIAS}

Alavi, M., \& Leidner, D. E. (2001). Knowledge management and knowledge management systems: conceptual foundations and research issues. MIS Quarterly, 25(1), 107-136.

Argyris, C., \& Schon, D. A. (1978). Organizational learning. Reading, MA: Addison-Wesley.

Barney, J., Wright, M., \& Ketchen, D. (2001). The resource-based view of the firm: ten years after. Strategic Management Journal, 27(6), 625-641.

Casadesus-Masanell, R., \& Ricard, J. E. (2010). From strategy to business models and onto tactics. Long Range Planning, 43, 195-215.

Chesbrough, H. W., \& Appleyard, M. M. (2007). Open innovation and strategy. California Management Review, 50(1), 57-76.

Cook, S. N. D., \& Brown, J.S. (1999). Bridging epistemologies: the generative dance between organizational knowledge and organizational knowing. Organization Science, 10(4), 381-400.

Davenport, T. H., \& Prusak, L. (1998). Working knowledge: how organizations manage what they know. Boston, MA: Harvard Business School Press.

Giesen, E., Riddleberger, E., Christner, R., \& Bell, R. (2010). When and how to innovate your business model. Strategy \& Leadership, 38(4), 17-26. 
Hacklin, F., \& Wallnöffer, M. (2012). The business model in the practice of strategic decision making: insights from a case study. Management Decision, 50(2), 166-188.

Hamel, G., \& Prahalad, C.K. (1994). Competing for the future. Boston, MA: Harvard Business School Press.

IBM. Global Business Services. (2006). Expanding the innovation horizon: the global CEO Study 2006. New York: IBM.

Johnson, M. W., Christensen, C. M., \& Kagerman, H. (2008). Reinventing your business model. Boston, MA: Harvard Business Review.

Kogut, B., \& Zander, U. (1992). Knowledge of the firm, combinative capabilities, and the replication of technology. Organization Science, 3(3), 383-397.

Lambert, S., \& Davidson, R. A. (2013). Applications of the business model in studies of enterprise success, innovation and classification: an analysis of empirical research from 1996 to 2010. European Management Journal, 31, 668-681.

Leonard-Barton, D. (1995). Wellsprings of knowledge: building and sustaining the sources of innovation. Boston, MA: Harvard Business School Press.

March, J.G., \& Olsen, J. P. (1976). Organizational learning and the ambiguity of the past: ambiguity and choice in organizations. Oslo, Norway: Universitetsfortaget.

McGrath, R. G. (2010). Business models: a discovery driven approach. Long Range Planning, 43, 247261.

Morris, M., Schindehutte, M. \& Allen, J. (2005). The entrepreneur's business model: toward a unified perspective. Journal of Business Research, 58, 726-735.

Nair, S., Nisar, A., Palacios, M. \& Ruiz, F. (2012). Impact of knowledge brokering on performance heterogeneity among business models. Management Decision, 50(9), 1649-1660.

Nolan Norton Institute. (1998). Putting the knowing organization to value. White Paper. Disponível em http://choo.ischool.utoronto.ca/Wittenburg/NolanNortonWP.pdf.

Nonaka, I. (1994). A dynamic theory of organizational knowledge creation. Organization Science, 5(1), 14-37.

Orlikowski, W. J. (2002). Knowing in practice: enacting a collective capability in distributed organizing. Organization Science, 13(3), 249-273.

Osterwalder, A. (2004). The business model ontology: a proposition in a design science approach. Unpublished doctoral dissertation, University of Lausanne, Lausanne, Switzerland.

Osterwalder, A., Pigneur, Y., \& Tucci, C. L. (2005). Clarifying business models: origins, present, and future of the concept. Communication of the Association for Information Systems, 16, 1-25.

Osterwalder, A., Pigneur, Y., \& Smith, A. (2010). Business model generation: a handbook for visionaries, game changers, and challengers. Hoboken, NJ: Wiley.

Polanyi, M. (1967). The Tacit Dimension. Chicago: University of Chicago Press.

Simon, H.A. (1991). Bounded rationality and organizational learning. Organization Science, 2(1), 125-134.

Sims, H.P., \& Gioia, D. A. J. (1986). The thinking organization: dynamics of organizational social cognition. San Francisco, CA: Jossey-Bass.

Sitkin, S.B. (1992). Learning through failure: the strategy of small losses. Research in Organizational Behavior, 14, 231-261.

Sosna, M., Trevinyo-Rodriguez, R. N., \& Velamuri, S. R. (2010). Business model innovation through trial-and-error learning. Long Range Planning, 43, 383-407. 
Spender, J. C. (1996). Making knowledge the basis of a dynamic theory of the firm. Strategic Management Journal, 17, 45-62.

Stewart, T.A. (1997). Intellectual capital: the new wealth of organizations. New York, NY: Doubleday.

Teece, D. J. (2010). Business models, business strategy and innovation. Long Range Planning, 43, 172194.

Tsoukas, H. (1996). The firm as a distributed knowledge system: a constructionist approach. Strategic Management Journal, 17, 11-25.

Voelpel, S.C., Leibold, M., \& Tekie, E.B. (2004). The wheel of business model reinvention: how to reshape your business model to leapfrog competitors. Journal of Change Management, 4(3), 259-276.

Weick, K. E. (1991). The nontraditional quality of organizational learning. Organization Science, 2 (1), $116-124$.

Weick, K. E., \& Roberts, K.H. (1993). Collective mind in organizations: heedful interrelating on flight decks. Administrative Science Quarterly, 38, 357-381.

Weick, K.E., \& Westley, F. (1996). Organizational learning: affirming an oxymoron: handbook of organization studies. Thousand Oaks, CA: SAGE.

Wernerfelt, B. (1984). A resource-based view of the firm. Strategic Management Journal, 5, 171-180.

Wirtz, B. W., Schilke, O., \& Ullrich, S. (2010). Strategic development of business models: implications of the web 2.0 for creating value on the Internet. Long Range Planning, 43, 272-290.

Yunus, M., Moingeon, B., \& Lehmann-Ortega, L. (2010). Building social business models: lessons from the Grameen experience. Long Range Planning, 43, 308-325.

Zack, M. (1998). What knowledge-problems can information technology help to solve. AMCIS 1998 Proceedings. Paper 216. Disponível em http://aisel.aisnet.org/amcis1998/216.

Zott, C., Amit, R. \& Massa, L. (2011). The business model: recent developments and future research. Journal of Management, 37(4), 1019-1042.

Zott, C., \& Amit, R. (2010). Business model design: an activity system perspective. Long Range Planning, 43, 216-226. 